\title{
Budget impact analysis of dabigatran compared with rivaroxaban in the prevention of the thromboembolic risk in patients with non-valvular atrial fibrillation
}

\author{
Maria Grazia Celeste ${ }^{1}$, Francesca De Marco ${ }^{2}$, Claudio Fresco ${ }^{3}$, Giuseppe Musumeci ${ }^{4}$, \\ Roberto Ravasio ${ }^{5}$ \\ ${ }^{1}$ UOC Farmacia Clinica, Fondazione PTV Policlinico Tor Vergata, Rome, Italy \\ ${ }^{2}$ UOC Pronto Soccorso e Breve Osservazione. Azienda Ospedaliera San Giovanni Addolorata, Rome, Italy \\ ${ }^{3}$ Dipartimento Cardiotoracico Azienda Sanitaria Universitaria Integrata di Udine, Udine, Italy \\ ${ }^{4}$ S.C. Cardiologia, Ospedale Santa Croce e Carle, Cuneo, Italy \\ ${ }^{5}$ Health Publishing \& Services Srl, Milan, Italy
}

\begin{abstract}
BACKGROUND: Dabigatran $150 \mathrm{mg}$ BID (D150) and rivaroxaban $20 \mathrm{mg}$ (R20) are indicated for the prevention of thromboembolic events in patients with Non-Valvular Atrial Fibrillation (NVAF). Outcomes from observational study demonstrated that D150 and R20 reduced the rate of thromboembolic events.

OBJECTIVE: This analysis estimated the budget impact of the use of D150 and R20 for the treatment of NAFV patients in Italy.

METHODS: A budget-impact model (BIM) was developed to estimate the direct costs up to 12 months from an Italian NHS perspective. The resource utilization (drugs and intracranial hemorrhage or major extracranial bleeding event) was derived from an observational study. Only direct medical costs were considered. Ex-factory prices and National Tariffs were considered to estimate the costs of drugs and medical resource used, respectively. The BIM showed the difference of expenditure and clinical events (intracranial hemorrhage or major extracranial bleeding) generated by the base case calculated for current prescription volumes (D150 30\%, R20 100\%), and for different prescription volume scenarios (D150 at $70 \%$ and $100 \%$ ). Key variables were tested in the sensitivity analysis.

RESULTS: D150 was associated with a medical cost offset driven by fewer intracranial hemorrhage and major extracranial bleeding event, these offset the incremental drug cost and results in an annual saving per patient treated (D150: $€$ 1,052.78; R20: $€ 1,161.23)$. The present scenario determines an annual cost of $€ 262,543,583$. The impact of total annual costs for the Italian NHS would be lower if D150 prescription volumes would be higher. The total cost is predicted to decrease by $3.8 \%$ if the D150 prescription increase to $70 \%$ and it is predicted to decrease by $6.7 \%$ if the D150 prescription increase to $100 \%$. CONCLUSION: The use of D150, as an alternative to R20 to prevent events in patients with NVAF, could represent a costsaving option for the Italian NHS.
\end{abstract}

Keywords

Dabigatran, Rivaroxaban; Non-Valvular Atrial Fibrillation; Budget impact analysis

\section{INTRODUCTION}

Oral anticoagulant treatment with either vitamin $\mathrm{K}$ antagonist or non-vitamin $\mathrm{K}$ antagonist is essential for the prevention of stroke or systemic embolism and all cause of mortality in patients with non-valvular atrial fibrillation. Direct thrombin inhibitor dabigatran etexilate (hereinafter referred to as "dabigatran")
[1] and direct factor Xa inhibitor rivaroxaban [2] are two non-vitamin $\mathrm{k}$ oral anticoagulants (NOACs). They showed a better efficacy profile compared to warfarin, as well as a greater simplicity of dosage, since they don't require a periodic monitoring of the prothrombin time (expressed through the INR - International Normalized Ratio - index) [3,4].
Corresponding author Roberto Ravasio rravasio@aboutpharma.com

Received: 11 September 2017 Accepted: 27 October 2017 
In the RE-LY study, 18,113 patients with Non-Valvular Atrial Fibrillation (NVAF) were followed for two years, with the aim of comparing dabigatran $150 \mathrm{mg}$ BID (bis in die) and $110 \mathrm{mg}$ BID vs warfarin [3]. The incidence of the events stroke or systemic embolism formed the primary efficacy endpoint investigated by the study, while the presence of major bleeding was the primary safety endpoint. In the comparison with warfarin, dabigatran $150 \mathrm{mg}$ significantly reduced the primary efficacy endpoint (Relative Risk - RR: 0.66; 95\% CI: 0.53-0.82; p < 0.001), while the improvement associated with dabigatran $110 \mathrm{mg}$ (RR: 0.91; 95\% CI: 0.74-1.11; $\mathrm{p}=0.34$ ) was not significant [3]. Dabigatran $150 \mathrm{mg}$ resulted in a borderline significant reduction in mortality (RR: $0.88 ; 95 \% \mathrm{CI}$ : 0.77-1.00; $p=0.051$ ) [3]. Again compared to warfarin, the reduction in the incidence of major bleeding with dabigatran $110 \mathrm{mg}$ was significant (RR dabigatran: $0.80 ; 95 \% \mathrm{CI}$ : $0.69-0.93 ; p=0.003)$, while it was not for dabigatran $150 \mathrm{mg}$ (RR: 0.93; 95\% CI: 0.81 1.07; $\mathrm{p}=0.31)$ [3].

The ROCKET-AF study observed - during a 19-month (mean) follow-up - 14,264

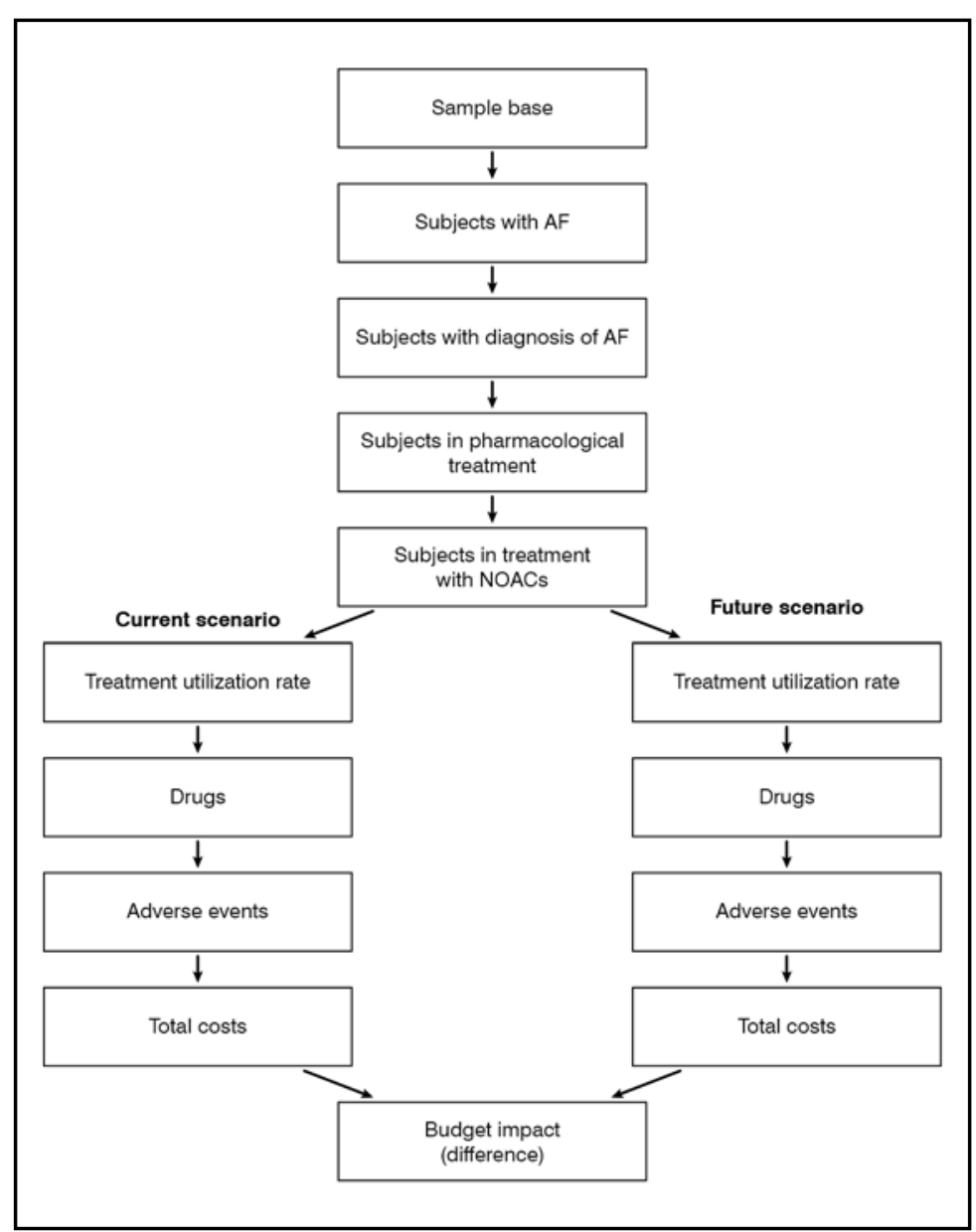

Figure 1. Budget Impact model structure $\mathrm{AF}=$ atrial fibrillation
NVAF patients treated with rivaroxaban 20 $\mathrm{mg}$ daily or warfarin [4]. Also in this case, the primary efficacy endpoint was the incidence of the events stroke or systemic embolism, while the primary safety endpoint was constituted by major or clinically relevant minor bleeding. In the Per-Protocol analysis, stroke or systemic embolism occurred in 188 patients receiving rivaroxaban $(1.7 \%$ per year) and in 241 patients receiving warfarin $(2.2 \%$ per year) (Hazard Ratio - HR: 0.79 ; 95\% CI: $0.66-0.96$; $p<0.001$ noninferiority) [4]. In the analysis referred to the Intention-To-Treat population (which included all events, from randomization to the completion of the study, regardless of how correctly patients had assumed the comparator drugs), a substantial equality between rivaroxaban and warfarin in the prevention of the primary efficacy endpoint was achieved (HR: 0.88; 95\% CI: 0.74-1.03; $p=0.12$ ) [4]. However, mortality from all causes $(4.5 \%$ and $4.9 \%$ per year, respectively; HR: 0.92 ; 95\% CI: $0.82-1.03 ; \mathrm{p}=0.15)$ and the primary safety endpoint $(14.9 \%$ and $14.5 \%$ per year, respectively; HR: 1.03 ; 95\% CI: 0.96-1.11; $\mathrm{p}=0.44$ ) did not show statistically significant differences between the two treatment groups [4].

Since the results of a recent economic evaluation conducted at national level suggest the cost-effectiveness of dabigatran and rivaroxaban compared with warfarin in the prevention treatment of NVAF patients [5], it seemed appropriate to assess the financial impact on the National Health Service (NHS), through a Budget Impact Analysis (BIA) aimed at estimating the sustainability. As a secondary objective, the BIA estimated the economic impact due to the use of idarucizumab in patients treated with dabigatran. Idarucizumab, in fact, is a monoclonal antibody used in the cases of emergency/urgency in which a rapid and specific inactivation of the anticoagulant effect of dabigatran is required [6].

\section{METHODS}

The BIA was conducted from the Italian NHS perspective. Direct healthcare consumption considered in the Budget Impact Model (BIM) describe, for NVAF patients, the cost of treatment with the two NOACs and the management of potential associated events, such as thromboembolic stroke, intracranial hemorrhage or major extracranial bleeding. The analysis did not consider other direct medical costs, nor indirect costs. The time horizon covered by the model is 1 year. The BIM structure is illustrated schematically in Figure 1. This BIA was carried out 
by following the Guidelines of the International Society for Pharmacoeconomics and Outcomes Research (ISPOR) $[7,8]$.

\section{Assumptions and input data}

\section{Clinical Data}

The clinical data used for the comparison between dabigatran and rivaroxaban derive from the results of the retrospective observational analysis conducted by Graham and colleagues [9]. This analysis was performed with the aim to compare the rates of risk for thromboembolic stroke, intracranial hemorrhage, major extracranial bleeding (including gastrointestinal bleeding) and mortality for NVAF patients in prevention treatment with dabigatran $150 \mathrm{mg}$ (BID) or with rivaroxaban $20 \mathrm{mg}$. Between November 2011 and June 2014, the analysis collected the data from 118,891 NVAF patients (Medicare) aged $\geq$ 65 , of which 52,240 being treated with dabigatran and 66,651 with rivaroxaban. Compared to dabigatran, the use of rivaroxaban resulted in a non-significant reduction in thromboembolic stroke (HR 95\% CI: 0.80; $p$ $=0.7$ ) and a significant increase in the risk for intracranial hemorrhage (HR 95\% CI: 1.58 ; $\mathrm{p}=0.002)$ and major extracranial bleeding (HR 95\% CI: 1.47 ; $<<0.001$ ), including gastrointestinal bleeding (HR 95\% CI: 1.39; $\mathrm{p}<$ 0.001).

From the study by Graham and colleagues, this analysis considered the efficacy data related to i) intracranial hemorrhages and ii) major extracranial bleeding; that is, the only events for which a statistically significant difference between the two pharmacological options considered here were identified [9].

\section{Population}

The number of patients was estimated starting from the population resident in Italy on $1^{\text {st }}$ January 2016 [10]. By applying a 2\% prevalence rate [11], the population with $\mathrm{AF}$ was then calculated. From this, through market surveys and IMS data $[12,13]$, it was possible to stratify the population to determine the number of NAVF patients treated with dabigatran $150 \mathrm{mg}$ and rivaroxaban $20 \mathrm{mg}$. Such selection was made so that the population subject of the BIM was homogenous to that considered in the study of Graham and colleagues [9], on which this analysis is based. This choice, however, has in actual fact excluded from the analysis the low doses of dabigatran $(110 \mathrm{mg})$, rivaroxaban $(15 \mathrm{mg})$ and two other NOACs (apixaban and edoxaban) with indication for the prevention treatment of NVAF patients. Table I shows in detail the flow of patients.

\begin{tabular}{lcc}
\hline & n. & Source \\
\hline Population resident in Italy on 1 January 2016 (n.) & $60,795,612$ & {$[10]$} \\
Patients with AF (2\%) & $1,215,912$ & {$[11]$} \\
Patients with diagnosis of AF (84\%) & $1,021,366$ & {$[12]$} \\
$\begin{array}{l}\text { Patients with diagnosis of AF in pharmacological } \\
\text { treatment (92\%) }\end{array}$ & 939,657 & {$[12]$} \\
$\begin{array}{l}\text { Patients with diagnosis of AF in pharmacological } \\
\text { treatment with NOACs (65\%) }\end{array}$ & 610,702 & {$[12]$} \\
$\begin{array}{l}\text { Patients in treatment with dabigatran (28.2\%) } \\
\text { - of whom in treatment with dabigatran 150 mg (40.8\%) }\end{array}$ & 70,295 & {$[13]$} \\
Patients in treatment with rivaroxaban (42\%) & 256,495 & {$[13]$} \\
- of whom in treatment with rivaroxaban 20 mg (63.3\%) & 162,361 & {$[13]$} \\
\hline
\end{tabular}

Tabella I. Population subject of the budget impact analysis

\section{Drugs}

In accordance with the time frame of one year, to which the risk rates estimated by the study of Graham and colleagues [9] are related, an administration period of 12 months was assumed for dabigatran and rivaroxaban, at an average daily dose of $150 \mathrm{mg}$ BID (two $150 \mathrm{mg}$ capsules) and $20 \mathrm{mg}$ (one $20 \mathrm{mg}$ tablet), respectively [9].

In the base case, an average cost per treatment day of $€ 2.23$ for dabigatran and $€ 2.20$ for rivaroxaban was considered. These costs reflect the relevant ex-factory prices, net of the discounts required by law $(-5 \%)$.

In the sensitivity analysis, two other scenarios that, instead, reflect alternative price hypotheses for the two NOACs are presented. In addition to the discounts required by law (base case), further discounts - negotiated between the Regulatory Body (AIFA, the Italian Drug Agency) and the Pharmaceutical Companies - were considered. Unlike what happens for rivaroxaban, whose net price is generated by the application of a confidential discount, the additional discount applied to dabigatran is composed of a fixed part (confidential discount for public facilities) and a variable portion, linked to a price-volume agreement. According to the price-volume agreement, additional incremental discounts are applied to the sale price to public structures, provided by the company in the form of payback, based on specific brackets of annual expenditure. In the first scenario, a parity price condition for the two treatments was simulated $[14,15]$. In the second, based on the most recent market data, we tried to present a situation that would reflect the actual sales prices to public structures of the two NOACs, a scenario in which dabigatran would have a lower average cost per treatment day compared to rivaroxaban $[14,15]$. 


\begin{tabular}{lcccc|cccc}
\hline & \multicolumn{3}{c}{ Without idarucizumab } & \multicolumn{5}{c}{ With idarucizumab } \\
\cline { 2 - 9 } & GI & IC & OB & ES & GI & IC & OB & ES \\
\hline Idarucizumab & 0.00 & 0.00 & 0.00 & 0.00 & $2,369.06$ & $2,369.06$ & $2,369.06$ & $2,369.06$ \\
Diagnostic & 93.13 & 125.50 & 42.00 & 31.27 & 93.13 & 125.50 & 42.00 & 31.27 \\
procedures & & & & & & & & \\
Treatments & $3,112.30$ & $3,769.07$ & $3,140.74$ & $1,098.29$ & 606,47 & 773,16 & 624,90 & 66,36 \\
Hospitalizations & $8,800.17$ & $8,800.17$ & $8,800.17$ & $1,855.25$ & $6,766.39$ & $8,800.17$ & $6,766.39$ & $10,859.48$ \\
Complications & 247.69 & 274.81 & 247.69 & 732.96 & 12.90 & 12.90 & 12.90 & 281.99 \\
ES & 0.00 & 0.00 & 0.00 & $6,047.47$ & 0.00 & 0.00 & 0.00 & $6,047.47$ \\
Total & $\mathbf{1 2 , 2 5 3 . 2 9}$ & $\mathbf{1 2 , 9 6 9 . 5 5}$ & $\mathbf{1 2 , 2 3 0 . 6 0}$ & $\mathbf{1 9 , 7 6 5 . 2 3}$ & $\mathbf{9 , 8 4 7 . 9 5}$ & $\mathbf{1 2 , 0 8 0 . 7 9}$ & $\mathbf{9 , 8 1 5 . 2 5}$ & $\mathbf{1 9 , 6 5 5 . 6 3}$ \\
\hline
\end{tabular}

Table II. Mean cost per patient without and with idarucizumab

$\mathrm{GI}$ = gastrointestinal bleeding; IC = intracranial bleeding; $\mathrm{OB}=$ other type of bleeding; $\mathrm{ES}=$ emergency surgery

\section{Number and cost of the events}

The BIM also provided an estimate of the average annual number of events associated with the two therapeutic strategies: intracranial hemorrhage and major extracranial bleeding. These events were subsequently quantified using the costs reported in a recent Italian analysis, which assessed the cost-effectiveness of the non-vitamin $k$ oral anticoagulants in the prevention therapy in NVAF patients [16]. An average cost of $€ 14,500$ for the intracranial hemorrhage event (this amount takes into account the management of a moderate stroke - Barthel Index $\leq 14$ and $\geq 10$ - and a possible disability) and $€$ $6,940.80$ for the major extracranial bleeding event were considered. By means of the sensitivity analysis, in addition to the base case, two other scenarios in which the event management cost was reduced first by $30 \%$ and then by $50 \%$ were evaluated.

\section{Market Share}

The market shares considered in the base case, equal to $30 \%$ and $70 \%$, respectively, represent the percentage of current use of dabigatran $150 \mathrm{mg}$ and rivaroxaban $20 \mathrm{mg}$ in the prevention treatment of NVAF patients $[12,13]$. These percentages were calculated by relating the number of patients treated with dabigatran $150 \mathrm{mg}(70,295)$ or rivaroxaban $20 \mathrm{mg}(162,361)$ to the total of patients considered in the BIM $(232,656)$ (Table I).

\begin{tabular}{lccc}
\hline \multirow{2}{*}{ Healthcare costs item } & \multicolumn{3}{c}{ Cost per patient (€) } \\
\cline { 2 - 4 } & $\begin{array}{c}\text { Dabigatran } \\
\mathbf{1 5 0} \mathbf{~ m g}\end{array}$ & $\begin{array}{c}\text { Rivaroxaban } \\
\mathbf{2 0 ~} \mathbf{~ m g}\end{array}$ & $\boldsymbol{\Delta}$ \\
\hline Drugs & 813.95 & 803.00 & 10.95 \\
Intracranial hemorrhage & 54.17 & 84.71 & -30.54 \\
Major extracranial bleeding & 184.65 & 273.52 & -88.87 \\
Total & $\mathbf{1 , 0 5 2 . 7 8}$ & $\mathbf{1 , 1 6 1 . 2 3}$ & $\mathbf{- 1 0 8 , 4 5}$ \\
\hline
\end{tabular}

Table III. Mean annual treatment cost
In addition to the base case - which had the purpose of providing a dimension of the current annual expenditure generated by the use of the two NOACs (high doses) in the prevention treatment of NVAF patients - two alternative scenarios are presented, in which the market share of dabigatran $150 \mathrm{mg}$ covers $70 \%$ or $100 \%$ of the patients treated. These alternative scenarios have the function to highlight the financial impact associated with a possible switch from rivaroxaban $20 \mathrm{mg}$ to dabigatran $150 \mathrm{mg}$.

\section{Impact of idarucizumab}

The economic impact borne by the NHS and generated by idarucizumab was evaluated only for the additional number of patients who, with regard to the base case, would be treated in the alternative scenarios (dabigatran $70 \%$ and $100 \%$ ), following the switch from rivaroxaban $20 \mathrm{mg}$ to dabigatran 150 $\mathrm{mg}$. The use of idarucizumab only for patients treated with dabigatran is in line with the current therapeutic indications of the product [6]. Idarucizumab is in fact a specific inactivator of dabigatran, in the cases where the rapid inactivation of its anticoagulant effects is necessary (emergency surgery/urgent procedures and life-threatening or uncontrolled bleeding). Most of the data used here to estimate the financial impact of idarucizumab refer to what was found by Belisari and colleagues [17]. Thanks to the results of the REVERSE AD study [18] and the data collected through the CORE-CINECA database [19], it is estimated that $0.48 \%$ of patients receiving dabigatran may cope with an emergency surgery (ES), while $1.05 \%$ can manifest uncontrolled or life-threatening bleeding events. The latter were divided into gastrointestinal bleeding (GI - 39.2\%), intracranial bleeding (IC $-35.3 \%)$ and other type of bleeding (OB $-25.5 \%$ ) [18]. The estimate of the healthcare resources needed for the management of uncontrolled or life-threatening bleeding 
and emergency surgery reproduces what was calculated by the study of Belisari and colleagues [17], to which it is hereby referred to for details. Table II shows the overall cost per patient treated for each of the events considered in the hypothesis of use or non-use of idarucizumab.

\section{Output data of the model}

\section{Budget Impact}

In relation to the estimated number of treatable patients and the average annual cost associated therewith (pharmacological treatment and management of events), the results of the BIM describe - during 12 months of analysis - the difference in the spending generated by the base case scenario with respect to two alternative scenarios, in which an increase in the market shares of dabigatran 150 $\mathrm{mg}(70 \%$ and $100 \%)$ is assumed. In addition to the expenditure data, the BIM provides for the same comparison also the variation in the number of events avoided (intracranial hemorrhage and major extracranial bleeding). Finally, as a secondary objective, the BIM presents the budget impact resulting from the use of idarucizumab in patients who were being treated with rivaroxaban $20 \mathrm{mg}$ and who were then switched to dabigatran $150 \mathrm{mg}$.

\section{RESULTS}

\section{Dabigatran vs rivaroxaban (base case)}

\section{Cost per patient treated}

The patient treated with dabigatran $150 \mathrm{mg}$ shows a reduction of $9.3 \%(€-108,45)$ in the mean annual cost with regard to that associated with the patient being treated with rivaroxaban $20 \mathrm{mg}$ (Table III). The higher cost associated with the drug therapy $(+1.4 \%$; $€$ $10.95)$ is completely offset by the lower cost for the management of intracranial hemorrhage $(-36.1 \%$; $€-30.54)$ and major extracranial bleeding (-32.5\%; $€-88.87)$.

\section{Expenditure borne by the NHS}

The annual expenditure borne by the NHS, calculated on the current number of patients in treatment with the two therapeutic strategies (dabigatran $150 \mathrm{mg}$ : $\mathrm{n} .=70,295$; rivaroxaban $20 \mathrm{mg}$ : $\mathrm{n}$. $=162,361)$ is equal to $€$ $262,543,628$, of which $€ 74,004,954$ generated by dabigatran $150 \mathrm{mg}$ and $€ 188,538,628$ by rivaroxaban $20 \mathrm{mg}$ (Figure 2). The number of events that would occur during the year would amount to 9,480, of which 1,211 due to intracranial bleeding and 8,268 to major extracranial bleeding (Figure 3 ).

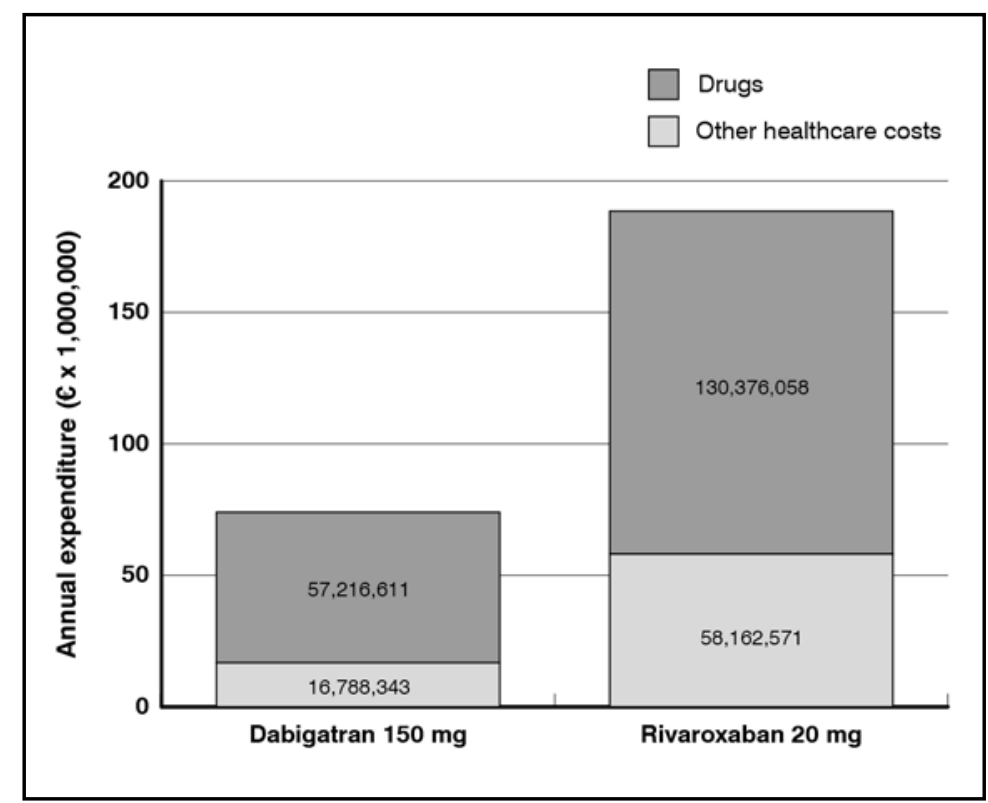

Figure 2. Annual expenditure borne by the NHS: base case scenario

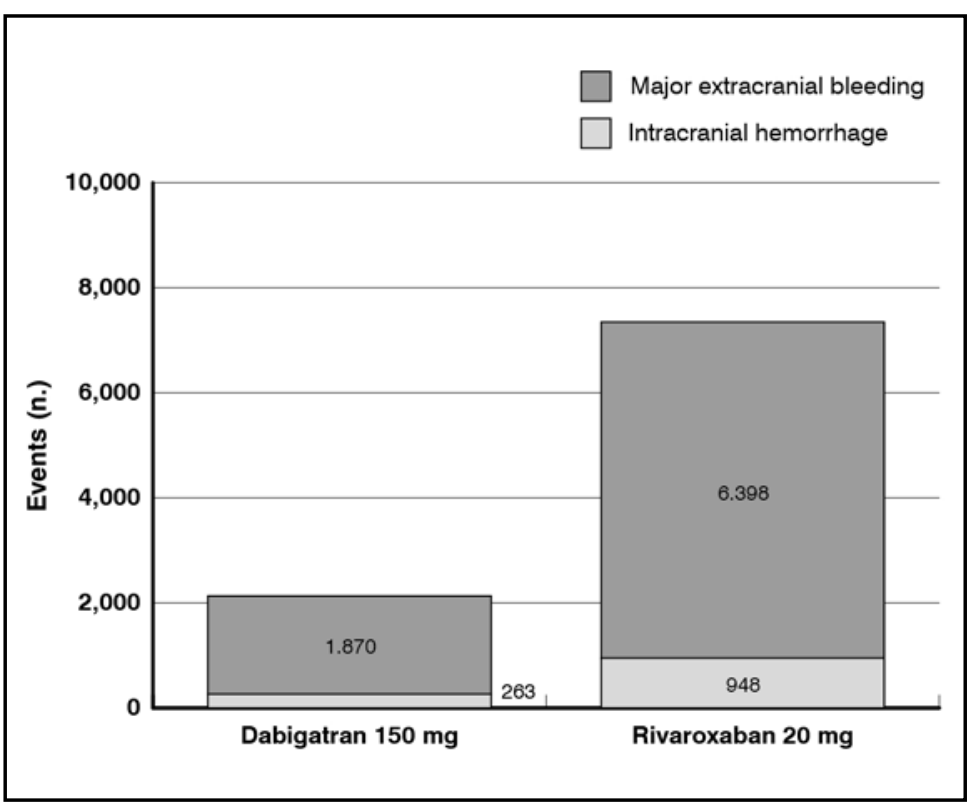

Figure 3. Number of events: base case scenario

In correspondence of an increase in the market share of dabigatran $150 \mathrm{mg}$ that, compared to the base case scenario, would lead to treat $70 \%$ or $100 \%$ of NVAF patients, there would be at the same time a significant reduction in the expenditure borne by the NHS (dabigatran $150 \mathrm{mg} 70 \%:-3.8 \%$ [€ -10,038,831]; dabigatran $150 \mathrm{mg} 100 \%$ : $-6.7 \%[€-17,608,472])$ and a slight increase in the number of the events avoided (dabigatran $150 \mathrm{mg} 70 \%$ : $+1,380$ events avoided;

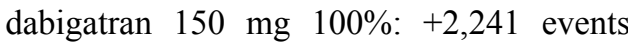
avoided) (Figure 4).

\section{Sensitivity analysis}

Table IV shows the main results of the sensitivity analysis. The two scenarios that in- 


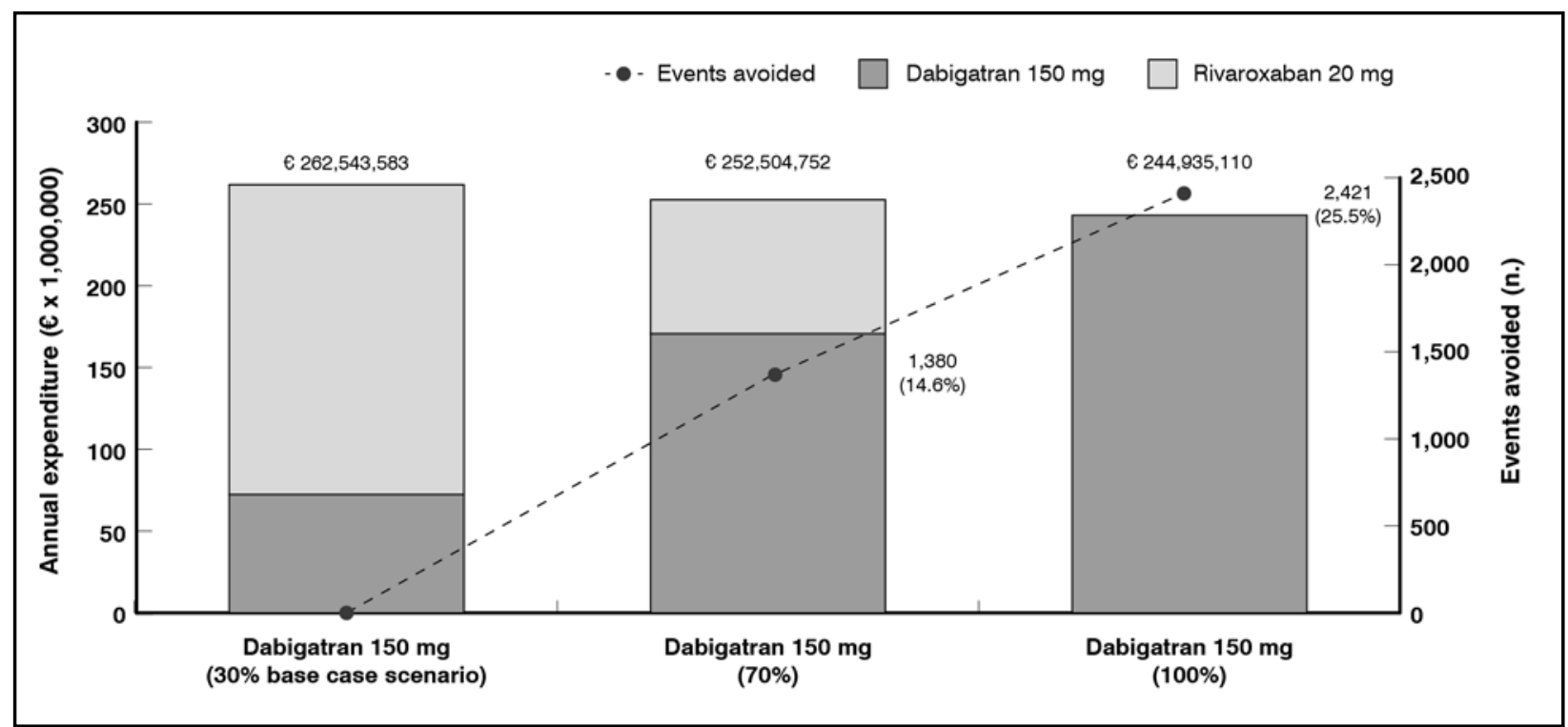

Figure 4. Annual expenditure borne by the NHS: base case scenario vs increase in the market share of dabigatran $150 \mathrm{mg}$

\begin{tabular}{|c|c|c|c|}
\hline Scenario & Vs base case ${ }^{1}$ & Vs dabigatran 150 mg 70\% ${ }^{2}$ & Vs dabigatran $150 \mathrm{mg} 100 \%^{2}$ \\
\hline Base case $(€)$ & $262,543,583$ & $252,504,752$ & $244,935,111$ \\
\hline - Variation (€) & & $-10,038,831$ & $-17,608,472$ \\
\hline - Variation (\%) & & -4.0 & -7.2 \\
\hline Parity price $(€)[14,15]$ & $217,615,704$ & $206,563,293$ & $198,229,376$ \\
\hline - Variation $(€)$ & $-44,927,879$ & $-11,052,411$ & $-19,386,328$ \\
\hline - Variation (\%) & $-17.1 \%$ & $-5.4 \%$ & $-9.8 \%$ \\
\hline Lower cost/die dabigatran $(€)[14,15]$ & $216,845,973$ & $204,779,983$ & $195,681,790$ \\
\hline - Variation (€) & $-45,697,610$ & $-12,065,991$ & $-21,164,183$ \\
\hline - Variation (\%) & -17.4 & -5.9 & -10.8 \\
\hline$-30 \%$ event costs $(€)^{3}$ & $240,058,309$ & $233,335,201$ & $228,265,735$ \\
\hline - Variation $(€)$ & $-22,485,274$ & $-6,723,108$ & $-11,792,574$ \\
\hline - Variation (\%) & -8.6 & -2.9 & -5.2 \\
\hline$-50 \%$ event costs $(€)^{3}$ & $225,068,126$ & $220,555,500$ & $217,152,817$ \\
\hline - Variation $(€)$ & $-37,475,457$ & $-4,512,626$ & $-7,915,309$ \\
\hline - Variation (\%) & -14.3 & -2.0 & -3.6 \\
\hline
\end{tabular}

Table IV. Sensitivity analysis

TVariations are calculated compared to the base case scenario

${ }^{2}$ Variations are calculated compared to the alternative scenarios

${ }^{3}$ Major extracranial bleeding and intracranial hemorrhage

volve the inclusion of additional discounts for dabigatran $150 \mathrm{mg}$ (discount to public facilities and price-volume agreement) and rivaroxaban $20 \mathrm{mg}$ (discount to public facilities) result in a reduction in the expenditure of around $17 \%$, compared to the base case. Compared to the base case, the $30 \%$ or $50 \%$ reduction in the costs considered to quantify intracranial hemorrhage and major extracranial bleeding causes a variation in the 8.6$14.3 \%$ range.

Considering instead the alternative scenarios, in which an increase in the number of patients treated with dabigatran $150 \mathrm{mg}(70 \%$ and $100 \%$ ) is assumed, no parameter determines any significant variations of the results vs the base case (never higher than 11\%). Finally, the situation in which all patients are treated with rivaroxaban $20 \mathrm{mg}$ was also evaluated. The expenditure for the NHS would increase by $2.9 \%$ compared to the base case ( $€ 270,167,248$ vs $€ 262,543,628)$, with an increase of $11.1 \%$ in the number of events $(10,528$ vs 9,480$)$.

\section{Idarucizumab}

In view of the increases in the number of patients treated with dabigatran $150 \mathrm{mg}$ assumed 
in the alternative scenarios (scenario $70 \%$ : $+92,564$ patients; scenario $100 \%$ : $+162,361$ patients) compared to the base case, 1,416 (scenario 70\%) and 2,484 (scenario 100\%) events would occur in which idarucizumab could be administered to quickly inactivate the anticoagulant effects of dabigatran (emergency surgery/urgent procedures and lifethreatening or uncontrolled bleeding) (Table $\mathrm{V})$. The use of idarucizumab would result in additional reductions in the treatment costs of $€ 1,868,758$ and $€ 3.277,870$, respectively (Table V).

\section{DISCUSSION AND CONCLUSIONS}

With the aim of providing a realistic scenario of the expenditure incurred by the NHS for the management of NAVF patients treated with dabigatran $150 \mathrm{mg}$ or rivaroxaban 20 $\mathrm{mg}$, the BIM did not only provide a financial estimate of the pharmacological costs alone, but - in a more extended perspective - also considered the costs associated with the management of intracranial hemorrhage and major extracranial bleeding, events for which a significant difference between the two NOACs was recorded [9]. With regard to the base case scenario, a greater use of dabigatran $150 \mathrm{mg}$ would lead to a reduction in both the healthcare expenditure borne by the NHS (dabigatran $150 \mathrm{mg} 70 \%$ : $-3.8 \%$; dabi-

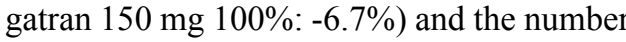
of intracranial hemorrhage (dabigatran 150

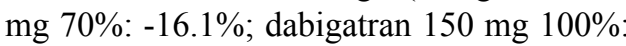
$-28.2 \%$ ) and major extracranial bleeding (dabigatran $150 \mathrm{mg} 70 \%$ : -14.3\%; dabigatran $150 \mathrm{mg}$ 100\%: -25.1\%).

The subsequent adoption of idarucizumab in the cases of additional patients treated with dabigatran, for whom the rapid inactivation of the anticoagulant effects becomes necessary, would result in a further reduction in the overall cost of the management of the clinical events (gastrointestinal, intracranial, extracranial bleeding and other type of bleeding) equal to about $€ 1.8$ million for the scenario dabigatran $150 \mathrm{mg}: 70 \%$ and $€ 3.3$ million for the scenario dabigatran $150 \mathrm{mg}: 100 \%$.

The dual effect determined by the increase in market shares of dabigatran $150 \mathrm{mg}$ and the use of idarucizumab would result in an overall reduction in the expenditure borne by the NHS of around $€ 12$ million (dabigatran $70 \%$ ) or $€ 21$ million (dabigatran $100 \%$ ) (Figure 5).

As is the case whenever it is necessary to use a simulation model, the results should be read in light of some remarks/limitations. Perhaps the most critical aspect is the choice of the clinical data used to populate the BIM. Since

\begin{tabular}{lcc}
\hline & \multicolumn{2}{c}{$\begin{array}{c}\text { Dabigatran } \\
\text { scenario }\end{array}$} \\
\cline { 2 - 3 } & $\mathbf{7 0} \%$ & $\mathbf{1 0 0 \%}$ \\
\hline Increases in the number of patients treated with & 92,564 & 162,361 \\
dabigatran 150 mg compared to rivaroxaban (n.) & & \\
Total events/year (n.) & 1,416 & 2,484 \\
• Gl bleeding & 381 & 669 \\
• Intracranial hemorrhage & 343 & 602 \\
• Other type of bleeding & 248 & 435 \\
• Emergency surgery & 444 & 779 \\
Costs (€) - Scenario without idarucizumab (A) & \\
• Gl bleeding & $4,670,309$ & $8,191,891$ \\
• Intracranial hemorrhage & $4,448,979$ & $7,803,670$ \\
• Other type of bleeding & $3,030,078$ & $5,314,867$ \\
• Emergency surgery & $8,781,869$ & $15,403,716$ \\
Total & $20,931,236$ & $36,714,144$ \\
Costs (€) - Scenario with idarucizumab (B) & & \\
• Gl bleeding & $3,753,518$ & $6,583,806$ \\
• Intracranial hemorrhage & $4,144,104$ & $7,268,907$ \\
• Other type of bleeding & $2,431,686$ & $4,265,265$ \\
• Emergency surgery & $8,733,170$ & $15,318,296$ \\
Total & $19,062,478$ & $33,436,274$ \\
Difference Scenario B - A & $\mathbf{- 1 , 8 6 8 , 7 5 8}$ & $\mathbf{- 3 , 2 7 7 , 8 7 0}$ \\
\hline
\end{tabular}

Table V. Economic impact of idarucizumab $\mathrm{Gl}=$ gastrointestinal

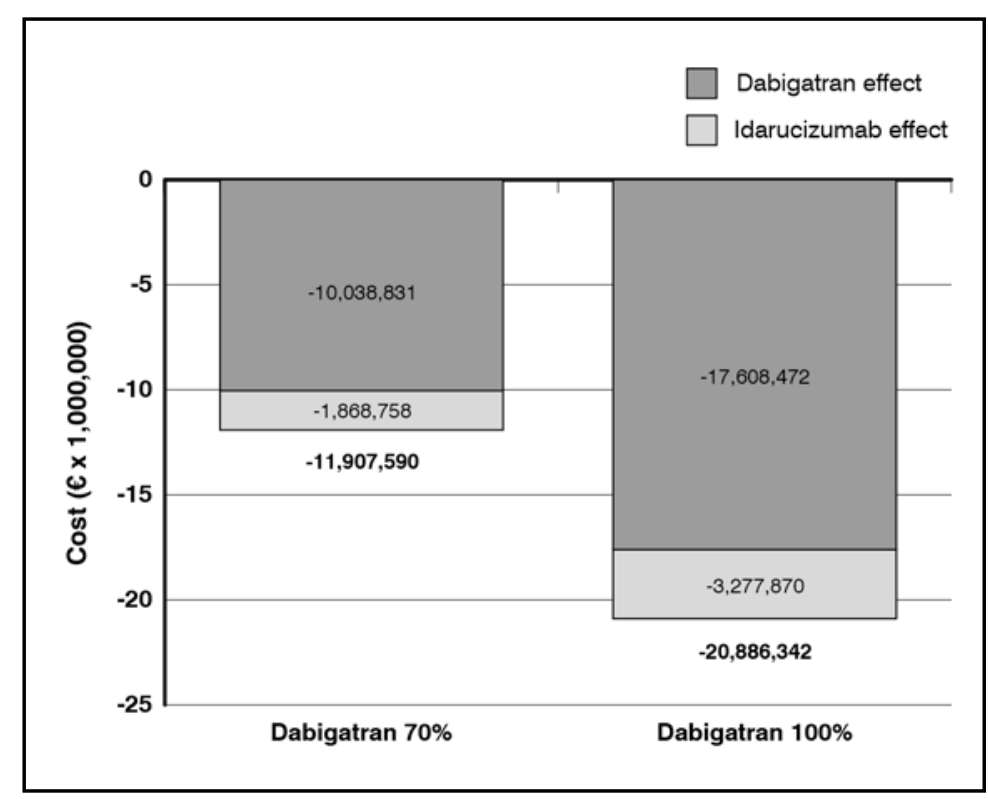

Figure 5. The dual effect determined by the increase in market shares of dabigatran and the use of idarucizumab

the objective of the analysis was the direct (head-to-head) comparison between the two molecules, the analysis focused on what was available in the literature. The two pivotal clinical trials were excluded because they had been conducted to estimate the efficacy and safety of dabigatran [3] or rivaroxaban 
[4] vs. warfarin alone. Also the results of subsequent indirect comparison studies were not considered suitable, since they had been conducted on non-homogeneous populations and therefore, in actual fact, were not comparable $[20,21]$. From the clinical studies, research was then directed towards real life observational analyses. Four large retrospective observational analyses were therefore identified, three conducted in Europe [22-24] and one in the United States [9]. The three European analyses, all carried out on Danish registers, concern approximately 140,000 patients diagnosed with NVAF in treatment with dabigatran $(150 \mathrm{mg} / 110 \mathrm{mg})$, rivaroxaban $(15 \mathrm{mg} / 20 \mathrm{mg})$, apixaban $(2.5 \mathrm{mg} / 5 \mathrm{mg})$ or warfarin. Despite the fact that they present an overall better efficacy profile (mortality rate, bleeding, or major bleeding) for dabigatran compared with rivaroxaban, in our view these analyses are characterized by a basic limitation of the study design, which in fact precluded their choice: clinical outcomes are always calculated with respect to warfarin, and not between NOACs [22-24]. Unlike the observational analysis of Graham and colleagues, conducted on approximately 120,000 patients enrolled in the Medicare program, it is the only one to have been conducted with the objective to compare directly dabigatran $150 \mathrm{mg}$ with rivaroxaban $20 \mathrm{mg}$, highlighting, when present, any significant differences between the two treatment groups [9]. For this reason, our choice fell on the latter observational analysis [9]. The adoption of the results of the observational analysis by Graham and colleagues [9], as a clinical basis of this budget impact model, is not in turn exempt from some criticism, such as the exclusion of the low doses of dabigatran (110 $\mathrm{mg}$ ) and rivaroxaban $(15 \mathrm{mg})$, the American patient case histories and the fact that it includes only patients aged over 65 . As a partial justification of these limits, it is emphasized that the observational analysis of Graham and colleagues [9] reflects results similar to those found by Larsen and colleagues [22] in the comparison between high doses of dabigatran and rivaroxaban.

The sensitivity analysis tried to overcome, as far as possible, the limitations associated with other assumptions adopted, such as the price of the drugs or the cost associated with the management of intracranial hemorrhage and major extracranial bleeding. All comparisons substantially confirmed the results of the base case.

A recent study [25] assessed the cost-effectiveness of dabigatran $150 \mathrm{mg}$ BID versus rivaroxaban $20 \mathrm{mg}$ QD for the treatment of patients with NVAF; the assessment was conducted using clinical events based on a US real-world evidence study by Graham et al. [9]. The same real-word data set was considered in our analysis. Patients on dabigatran were found to experience fewer bleeding events than patients on rivaroxaban. This lower incidence in bleeding events led to lower costs among dabigatran which in turn was the key driver in the US study conclusion that dabigatran was dominant over rivaroxaban in the US Medicare setting.

In conclusion, we believe that this analysis presents a reliable scenario - deriving from the use of dabigatran $150 \mathrm{mg}$ and rivaroxaban $20 \mathrm{mg}$ in the treatment of NAVF patients in Italy - of how a larger prescription of dabigatran $150 \mathrm{mg}$ may result in a lower cost for the NHS. Since this analysis is one of the first attempts, it would be desirable, in the near future, to be able to confirm this result against what will be evidenced by the clinical practice. Data obtained from Italian registers will in fact be able to definitively validate the analyses deriving from the impact budget models.

\section{Funding}

This research was made possible by an educational grant from Boehringer Ingelheim Italia S.p.A.

\section{Conflict of interest}

The authors have no conflict of interest to declare.

\section{REFERENCES}

1. Pradaxa - Prescribing Information. Ridgefield, CT: Boehringer Ingelheim; 2012. Available at: http://www.accessdata. fda.gov/drugsatfda_docs/label/2012/022512s011lbl.pdf (last accessed April 2017)

2. Xarelto - Prescribing Information. Leverkusen, Germany: Janssen; 2011. Available at: http://www.xareltohcp.com/ shared/product/xarelto/prescribing-information.pdf (last accessed April 2017)

3. Connolly SJ, Ezekowitz MD, Yusuf S, et al. RE-LY Steering Committee and Investigators. Dabigatran versus warfarin in patients with atrial fibrillation. N Engl JMed 2009; 361: 1139-51; https://doi.org/10.1056/NEJMoa0905561

4. Patel MR, Mahaffey KW, Garg J, et al; ROCKET AF Investigators. Rivaroxaban versus warfarin in nonvalvular atrial fibrillation. N Engl J Med 2011; 365: 883-91; https://doi.org/10.1056/NEJMoa1009638 
5. Rognoni C, Marchetti M, Quaglini S, et al. Apixaban, dabigatran, and rivaroxaban versus warfarin for stroke prevention in non-valvular atrial fibrillation: a cost-effectiveness analysis. Clin Drug Investig 2014; 34: 9-17; https:// doi.org/10.1007/s40261-013-0144-3

6. Pollack CV Jr, Reilly PA, Eikelboom J, et al. Idarucizumab for Dabigatran Reversal. $N$ Engl J Med 2015; 373: 511-20; https://doi.org/10.1056/NEJMoa1502000

7. Mauskopf JA, Sullivan SD, Annemans L, et al. Principles of good practice for budget impact analysis: report of the ISPOR Task Force on Good Research Practices — budget impact analysis. Value Health 2007; 10: 336-47; https:// doi.org/10.1111/j.1524-4733.2007.00187.x

8. Sullivan SD, Mauskopf JA, Augustovski F, et al. Budget impact analysis principles of good practice: report of the ISPOR 2012 Budget Impact Analysis Good Practice II Task Force. Value Health 2014; 17: 5-14; https://doi. org/10.1016/j.jval.2013.08.2291

9. Graham DJ, Reichman ME, Wernecke M, et al. Stroke, Bleeding, and Mortality Risks in Elderly Medicare Beneficiaries Treated With Dabigatran or Rivaroxaban for Nonvalvular Atrial Fibrillation. JAMA Intern Med 2016; 176: 1662-71; https://doi.org/10.1001/jamainternmed.2016.5954

10. ISTAT Popolazione residente 1 gennaio 2016. Available at: http://dati.istat.it/Index.aspx?DataSetCode=DCIS_POPRES1 (last accessed August 2016)

11. Davis RC, Hobbs FD, Kenkre JE, et al. Prevalence of atrial fibrillation in the general population and in high-risk groups: the ECHOES study. Europace 2012; 14: 1553-9; https://doi.org/10.1093/europace/eus087

12. IMS Health S.p.A. Estimation from Market Dynamics (IMS) in line with actual trend

13. IMS Health S.p.A. IMS analysis on sold packages in AF market

14. Data on file. IHS Markit

15. Data on file. Boehringer Ingelheim

16. Ravasio R, Pedone MP, Ratti M. Cost efficacy analysis of new oral anticoagulant for stroke prevention in non-valvular atrial fibrillation in Italy. PharmacoEcon Ital Res Artic 2014; 16: 22; https://doi.org/10.1007/s40276-014-0022-x

17. Belisari A, Iannazzo S, Di Pasquale G, et al. Budget impact analysis of idarucizumab for the management of patients treated with dabigatran in emergency / urgent situations in Italy. Farmeconomia. Health economics and therapeutic pathways 2016; 17: 47-58; https://doi.org/10.7175/fe.v17i2.1243

18. Pollack CV Jr, Reilly PA, van Ryn J, et al. Idarucizumab for Dabigatran Reversal - Full Cohort Analysis. $N$ Engl $J$ Med 2017; 377: 431-41; https://doi.org/10.1056/NEJMoa1707278

19. Database CORE (Collaborative Outcome Research) CINECA

20. Lip GYH, Larsen TB, Skjøth F, et al. Indirect comparisons of new oral anticoagulant drugs for efficacy and safety when used for stroke prevention in atrial fibrillation. J Am Coll Cardiol 2012; 60: 738-46; https://doi.org/10.1016/j. jacc.2012.03.019

21. Schneeweiss S, Gagne JJ, Patrick AR, et al. Comparative efficacy and safety of new oral anticoagulants in patients with atrial fibrillation. Circ Cardiovasc Qual Outcomes 2012; 5: 480-6; https://doi.org/10.1161/CIRCOUTCOMES.112.965988

22. Larsen TB, Skjøth F, Nielsen PB, et al. Comparative effectiveness and safety of non-vitamin $\mathrm{K}$ antagonist oral anticoagulants and warfarin in patients with atrial fibrillation: propensity weighted nationwide cohort study. $B M J$ 2016; 353: i3189; https://doi.org/10.1136/bmj.i3189

23. Gorst-Rasmussen A, Lip GY, Bjerregaard Larsen T. Rivaroxaban versus warfarin and dabigatran in atrial fibrillation: comparative effectiveness and safety in Danish routine care. Pharmacoepidemiol Drug Saf 2016; 25: 1236-44; https://doi.org/10.1002/pds.4034

24. Nielsen PB, Skjøth F, Søgaard M, et al. Effectiveness and safety of reduced dose non-vitamin K antagonist oral anticoagulants and warfarin in patients with atrial fibrillation: propensity weighted nationwide cohort study. $B M J$ 2017; 356: j510; https://doi.org/10.1136/bmj.j510

25. Peng S, Deger KA, Ustyugova A, et al. Cost-effectiveness analysis of dabigatran versus rivaroxaban for stroke prevention in patients with non-valvular atrial fibrillation using real-world evidence in elderly US Medicare beneficiaries. Curr Med Res Opin 2017; 26: 1-9; https://doi.org/10.1080/03007995.2017.1375470 